\title{
Revisitando a identidade do relacionamento marca-consumidor: repensando as estruturas nessas relações comerciais
}

\author{
Revisiting brand-consumer Identity: Rethinking the frameworks of these \\ commercial relationships
}

\author{
Sérgio C. Benício de Mello ${ }^{1}$ \\ Francisco Ricardo Bezerra Fonsêca
}

\begin{abstract}
Resumo
Na literatura de marketing de relacionamento, o construto identidade é vital para compreendermos a(s) maneira(s) pela(s) qual(is) as relações comerciais são iniciadas, desenvolvidas, mantidas e dissolvidas ao longo do tempo. Este artigo visa desvelar o significado da identidade do relacionamento marca-consumidor, com vistas a compreender que propriedades relacionais são consideradas relevantes pelos parceiros que pretenderem se engajar em uma relação dessa natureza.

O estudo foi realizado por meio de abordagem qualitativa, inspirada no método fenomenológico, efetuando-se entrevistas em profundidade com gerentes de uma grande rede de fast-food. No plano analítico foi utilizada a redução fenomenológica visando à identificação da essência da identidade desse relacionamento e à interpretação de seus significados. Nas interações marca-consumidor, as propriedades relacionais identificadas com o construto identidade foram: identificação, valência e relevância, marca-signo, convergência de valores e reconhecimento. Em suma, ao proporcionar aos parceiros o emergir da confiança, do espaço social da "casa", da identificação, por exemplo, a identidade do relacionamento assegura a longevidade do mesmo.
\end{abstract}

Palavras-chave: relacionamento marca-consumidor; identidade; fenomenologia.

\begin{abstract}
In the relationship marketing literature, identity is a vital construct in understanding how commercial relationships are initiated, developed, maintained and dissolved over time. This paper aims the clarification of meaning(s) of the brandconsumer relationship identity, in order to comprehend which relational properties are relevant to partners who intend to engage in relationship. This qualitative study was accomplished through in-depth interviews inspired by the phenomenological method. In the analytical scope, a phenomenological reduction was undertaken to reveal the essence of brand-consumer identity, as well as the interpretation of its meaning. Within brand-consumer interactions the properties identified with the Identity construct were: identification, valence and relevance, brand-sign, convergence of values, and recognition. In conclusion, when relationship identity propitiates the emergence of trust within a special type of social space and identification, for example, it assures the existence of the relationship in a long-term.
\end{abstract}

Key words: brand-consumer relationship; identity; phenomenology.

\footnotetext{
${ }^{1}$ Ph.D em Marketing pela City University London (Cass Business Schoo), Reino Unido. Pesquisador do CNPq, membro da comissão de avaliação de área da CAPES, professor associado 1 da Universidade Federal de Pernambuco (UFPE), lotado no Departamento de Ciências Administrativas (DCA) e coordenador do grupo de pesquisa Grupo de Estudo e Pesquisa em Tecnologia, Estudos Culturais e Consumo (GTEC/UFPE). Endereço: DCA/CCSA/UFPE - Av. Prof. Moraes Rego, ${ }^{\circ}$ 1235 Cidade Universitária - Recife - Pernambuco - Brasil - CEP: 50670-901. E-mail: sergio.mello@ufpe.br

${ }^{2}$ Mestre em Administração de Empresas pela Universidade Federal de Pernambuco (UFPE), professor assistente 1 da UFPE, lotado no Campus Acadêmico do Agreste (CAA) e pesquisador do grupo de pesquisa Grupo de Estudo e Pesquisa em Tecnologia, Estudos Culturais e Consumo (GTEC/UFPE). Endereço: CAAG/Núcleo de Gestão/UFPE. Endereço: Rodovia BR 104 km 62 s/n, Pólo Comercial - Nova Caruaru - Caruaru - Pernambuco - Brasil CEP: $55014-170$ - E-mail: ricardofonseca01@gmail.com

Artigo submetido em: junho de 2008 e aprovado em agosto de 2008
} 


\section{Introdução}

Na sociedade contemporânea, o consumo ocupa um lugar central em nossas vidas. Ele vem sendo utilizado para designar quase todos os mecanismos e processos sociais (e.g., reprodução social, construção de subjetividades e identidades) em que estamos envolvidos. É difícil imaginar um indivíduo que realize suas atividades diárias sem utilizar, necessitar, ou, quiçá, desejar os objetos de consumo [marcas] (cf. HOLBROOK, 2001). Conforme Barbosa e Campbell (2006), o consumo pode ser entendido como um mecanismo social produtor de sentido e de identidades, independentemente da aquisição de uma marca; uma estratégia utilizada diariamente pelos consumidores para definir diversas situações em termos de direitos, estilo de vida e identidades.

Dessa perspectiva, os consumidores [re]constroem sua identidade (self) com base nas experiências de consumo com as marcas e vice-versa. Os relacionamentos comerciais desempenham um papel fundamental na constituição da identidade desses parceiros, posto que, é por meio dessas relações que essas experiências acontecem (SOUZA NETO et al, 2004). Ao cederem (ofertarem para consumo) e compartilharem suas imagens (signos e valores semânticos) com os consumidores, as marcas auxiliam esses consumidores a poderem ser "quem querem ser ou parecer ser". Essas imagens nada mais são do que a representação da identidade refletida da marca. Vale salientar que essa identidade pode ser [pré]fabricada e comunicada pelas estratégias de marketing (EM) das corporações.

Os consumidores podem atuar de duas formas no processo de [re]constituição da identidade da marca: legitimando a identidade "imposta" pelas EM ou sugerindo à marca novos traços identitários, ainda não contemplados pelas corporações, como por exemplo, novas ocasiões de uso da marca e traços de personalidade (cf. AMBLER et al, 2002, FONSÊCA e MELLO, 2005; KARJALAINEN, 2003).

Diante do exposto, compreender o processo de [re]construção de identidade é vital para entendermos um dos possíveis porquês dos consumidores iniciarem, continuarem ou desfazerem o relacionamento com uma marca ao longo do tempo. Além disso, possibilita entender que ações a marca tem promovido ou deveria promover para construir uma identidade que crie empatia/identificação com o consumidor.

Nesse sentido, sabemos que as relações de marketing tendem a perdurar, à medida que os consumidores se identifiquem tanto com a identidade comunicada pela marca, quanto com aquela refletida pelo relacionamento em si ["nós"] (AGGARWAL; LAW, 2005). Ora, as pessoas tendem a interagir (estabelecendo relações utilitárias ou hedônicas) com pessoas ou marcas que lhes despertem uma identificação, a ponto de fazerem afirmações do tipo "Fulano é minha cara metade!", "Essa marca foi feita para mim!" ou "Esse é o casamento dos meus sonhos!" Portanto, para potencializar a longevidade do relacionamento, o papel da marca é [re]inventar - conjuntamente com o consumidor - a estrutura de sua identidade, fazendo com que este sempre a perceba como seu objeto de desejo (BLACKSTON, 1993; PATTERSON; O’MALLEY, 2006).

Para investigar a identidade dos relacionamentos de marketing ["nós"] é necessário entender que ela é fruto da simbiose das identidades da marca e do consumidor. Por ser concebida a partir de processos sociais, a identidade do "nós" (IN) é formada, moldada, reforçada ou compartilhada pelos parceiros, à proporção que eles interagem entre si. Ao mesmo tempo, a IN influência e impacta as identidades de cada parceiro, a ponto de modificá-las ou ratificá-las (cf. KARJALAINEN, 2003; KELLER, 2002).

Ora, pensemos em um casamento: a identidade do casal (IC) é fruto do compartilhamento de significados derivados das interações entre as identidades de João e Maria. Apesar da IC possuir comunalidades com as identidades de João e Maria, a identidade do relacionamento é distinta das identidades dos parceiros, posto que ela possui certas características e traços identitários, os quais não estão necessariamente presentes nas identidades do esposo e da esposa. Embora a identidade de João seja distinta das identidades de Maria e do casal, a identidade do esposo é construída, constituída e influenciada pela identidade da esposa e do casal, sendo a mesma lógica aplicada a ela (PALMER, 1996). Vale salientar que a identidade do relacionamento e dos parceiros pode ser modificada no decorrer das interações entre eles. 
Apesar dos argumentos apresentados anteriormente, poucos foram os estudos em marketing de relacionamento (MR) que, de fato, investigaram a identidade dos relacionamentos comerciais, muito menos, num dos seus subconjuntos que é o relacionamento marca-consumidor (FONSÊCA; SOUZA NETO, 2007; PATTERSON; O'MALLEY, 2006). A maior parte dos textos, que versam sobre a identidade da relação, tem adotado uma perspectiva estática e unilateral de operacionalização de um fenômeno tão complexo, dinâmico e dialógico (FOURNIER, 1998). Em outras palavras, ora os estudos enfocam o ponto de vista do consumidor (eu) acerca da marca (outro), ora o dela (eu) em relação aos seus consumidores (outro); raramente, enfocam a perspectiva da díade (nós) ou a perspectiva dos parceiros (eus) - isoladamente - quanto à relação (nós) em que estão engajados. Dessa maneira, não devemos compreender tal identidade baseados apenas na percepção que a marca (personificada no relacionamento por meio da voz do funcionário) possui do consumidor e vice-versa, mas temos, sim, que investigar também a maneira como eles percebem o "nós" (FONSÊCA; MELLO, 2005; SOUZA NETO et al, 2004;).

Baseado nos argumentos apresentados, as propostas deste artigo são: 1) identificar as estruturas identitárias constituintes do relacionamento marca-consumidor; 2) desvelar o(s) significado(s) dessas estruturas, com vistas a compreender a identidade e o processo de identificação dessa relação.

\section{Uma breve explanação sobre o conceito de identidade}

Os problemas que se apresentam hoje em dia são mais complexos que aqueles de há 20 anos. Responder a pergunta "quem sou eu?", conseguir definir o "verdadeiro você" tornou-se uma tormenta, haja vista que, de certa forma, cada um de nós é, na verdade, uma série de diferentes personalidades, as quais podem ser complementares ou antagônicas. Temos tantos "eus" quanto nossos diferentes papéis sociais. Dependendo da situação, agimos de modos diferentes, consumimos diferentes produtos, temos gostos diferenciados (SOLOMON, 1983). Por conta disso, são necessários, portanto, conceitos mais afinados acerca da identidade da marca, do consumidor e do relacionamento marca-consumidor, para permitir uma melhor visão da realidade.

Inicialmente, a identidade pode ser entendida como um conjunto de características definidoras da personalidade de uma entidade em relação à outra. Avançando um pouco mais, observamos que a identidade focaliza tanto as diferenças, como os traços comuns entre marca e consumidor, os quais assumem certa identidade diante desses mesmos traços comuns e o relacionamento (cf. DeCHERNATONY, 1999; GOULDING; SHANKAR; ELLIOT, 2002).

A identidade do consumidor é geralmente definida com base no seu estilo de vida, nas suas crenças, atitudes e nos seus valores e traços de personalidade, por exemplo. O modo como o consumidor define seus próprios atributos, como avalia suas próprias qualidades (autoconceito), em grande parte, envolve as descrições que faz de si próprio quanto às características definidoras dos grupos sociais (e.g., comunidades de marca, família e amigos) a que pertence (SIRGY, 1982). Já a identidade da marca integra todo o conjunto de características que lhe são específicas, resultantes da sua história, dos seus valores, das suas propriedades, do seu aspecto físico e da relação que mantém com o público, por exemplo (KAPFERER, 1997). Em suma, dela fariam parte todas aquelas características tangíveis e intangíveis que a empresa atribuiu a sua marca e que procura comunicar ao consumidor.

Por ser construída socialmente, a identidade dos parceiros é cunhada por uma mescla entre as especificidades que os diferenciam, assim como os traços que compartilham ao longo do relacionamento. Nesse contexto, é por meio da identidade que os parceiros relacionais constroem seu autoconceito, sinalizando quem eles são ou "querem ser" para si e para o outro. Vale ressaltar que as identidades não são estáticas; logo, encontram-se submetidas a uma historicização, a qual sugere a necessidade constante de processos de mudança. Para compreender o processo de mutação da identidade, é preciso examiná-la em suas diferentes dimensões pessoal, social e cultural -, cada qual responsável por formar o autoconceito dos parceiros (ELLIOT; WATTANASUWAN, 1998). Baseado no que fora dito até aqui e na assertiva de que "cada relação é única em si mesmo", conceituaremos a identidade do relacionamento marca-consumidor como o conjunto específico de características (e.g., atributos, propriedades, valores, artefatos, traços de personalidade e normas próprias) que distingue essa relação das demais. A identidade da relação é pautada pelo modo como os parceiros avaliam o 
fato de pertencerem a determinado grupo social, ao mesmo tempo em que essa condição de membro tem uma significância emocional e implica atribuir-lhe um juízo de valor por parte desses parceiros (cf. FOURNIER et al., 2001).

\section{Definindo o relacionamento marca-consumidor}

Inspiradas na literatura de relacionamento marca-consumidor, as corporações - para conseguirem estabelecer relações duradouras com os consumidores - constroem suas marcas baseando-se na perspectiva destes (ver BLACKSTON, 1992; KELLER, 2002). Isso possibilita que modem a identidade de suas marcas ao gosto dos consumidores, levando em consideração aquilo que eles valorizam, desejam e o que necessitam delas (AMBLER et al, 2002; DALL'OLMO REILLY; DeCHERNATONY, 2000).

Por esse prisma, a premissa básica da construção do "nós" (i.e., relação) reside na forma como a marca é percebida pelos consumidores. Em outras palavras, o existir desse relacionamento depende daquilo que os consumidores tenham aprendido, sentido, visto e ouvido sobre a marca, como um resultado de suas experiências cotidianas (e.g.: a propaganda da marca, o contato com funcionário de linha de frente, as experiências pessoais com amigos e o boca a boca) com a marca (FOURNIER, 1994). Essa relação é estabelecida à proporção que o consumidor perceba que sua vivência com a marca foi e é benéfico (GRÖNROOS, 2000).

Para efeitos deste artigo, definiremos o relacionamento marca-consumidor como o conjunto de relações mutuamente compartilhadas entre consumidores e marca (FOURNIER, 1998). Essa dinâmica relacional perpassa a simples interação entre esses parceiros, e, de fato, a longevidade do relacionamento dependerá da forma como o consumidor percebe a marca, bem como a maneira como ele crê que a marca o percebe, e viceversa (cf. BLACKSTON, 1993). Nesse contexto, tal relacionamento pode ser compreendido pela analogia com a complexidade cognitiva, afetiva e processual-comportamental das pessoas; processos esses que constituem e permeiam as relações interpessoais (FONSÊCA, 2006; PATTERSON; O'MALLEY, 2006). De fato, conforme esses autores, a metáfora interpessoal é perfeitamente aplicada a esse tipo de relacionamento no contexto de serviço, posto que, os funcionários de contato - nos encontros de serviços - tendem a personificar a marca ao interagirem com os consumidores. Por sua vez, ao perceberem isso, os consumidores antropomorfizam a marca, tornando-a um "ser vivo", dignificando-a com "humanidade".

Pelo fato da construção da identidade do relacionamento marca-consumidor ocorrer por um processo comunicacional, nas próximas seções serão apresentados dois modelos teóricos que objetivam explicar a dinâmica desse fenômeno: 1) o modelo de comunicação baseado no processo de codificação e decodificação entre identidade-imagem (vigente na área de marketing) e 2) o modelo de construção social da identidade (modelagem concorrente na área de marketing).

\section{A construção da identidade da relação marca-consumidor na ótica da visão tradicional de marketing de relacionamento}

De acordo com Bengtsson (2003), Fonsêca (2006) e Gummeson (2002), devido à natureza da relação marcaconsumidor ser essencialmente parassocial, ${ }^{1}$ sua identidade é construída sob a batuta do modelo básico de comunicação entre identidade e imagem. Para Kapferer (1997), a identidade é um conceito de emissão. Trata-se de especificar o sentido e a concepção da marca. A imagem é um conceito de recepção, é o resultado, uma decodificação. É aquilo que o público decodifica do conjunto de símbolos provenientes da marca, uma interpretação (Patterson, 1999).

De acordo com essa modelagem, a comunicação entre a marca e o consumidor pode ser examinada em termos de: a marca (fonte) codifica e comunica (por intermédio de mídias e pontos de contato) a identidade da relação para o consumidor (receptor), que a decodifica com base na sua percepção, formando uma imagem, cuja interpretação deve ser a mais fidedigna possível com o que lhe foi comunicado. As "falhas" de comunicação podem existir quando há discrepâncias entre o processo de codificação e de decodificação (cf. 
DeCHERNATONY, 1999). Essa relação não passaria de uma simulação dos relacionamentos interpessoais, não propiciando aos parceiros uma contrução (conjunta, mútua, instantânea e consensual) da identidade do "nós", como ocorre nas interações entre duas pessoas.

Diante do exposto, nos relacionamentos parassociais marca-consumidor, conforme Gummeson (2002), a construção da identidade do "nós" é preponderantemente uma criação da marca. Quando analisamos a lógica proposta por Blackston (1993) e Keller (2002), por exemplo, verificamos que a marca pré-molda sua estrutura e a relação, baseada nas necessidades e desejos do consumidor, esperando que ele aceite (passivamente) e legitime a identidade "imposta" por ela. Ao consumidor cabe apenas a decisão de aceitar ou não essa identidade (gerar a imagem) e ingressar nesse relacionamento pré-moldado. Ao concordar em se engajar na relação, ele torna-se apenas um "observador passivo", o qual só assume sua "condição ativa" quando "a estrutura por trás da marca" (i.e., EMA) ou a marca lhe solicita isso (GUMMESON, 2002; MELLO; FONSÊCA, 2007). Como nas relações parassociais, a interação entre os parceiros é mediada e os ajustes e adaptações, quando ocorrem, são realizados com "atraso", pelo fato da relação não ser suscetível ao desenvolvimento mútuo. A marca só refletirá (com intuito de mudanças) sobre suas características, crenças e ações (i.e., tipificações), caso os consumidores não se identifiquem com (determinadas) tipificações da mesma. A relação torna-se, então, assimétrica com o controle da relação quase de cunho exclusivo da marca. $\mathrm{O}$ consumidor teria diminuto poder para criar a identidade da relação com a marca, possuindo (se quiser manter a relação) a opção de "aceitar" e participar do mundo que é construído para ele. Isso não significa que ele tenha de "aceitar" sempre essa identidade do "nós"; caso não queira, pode escolher dissolver ou não ingressar na relação (cf. BENGTSSON Keller (2002), 2003).

\section{A construção social da identidade do fenômeno relacional marca-consumidor}

Dessa perspectiva, o relacionamento marca-consumidor ocorre quando há interação, comunicação e compartilhamento das tipificações (e.g., crenças, valores, personalidades, estilos de vida, atitudes, traços e características) de forma e conteúdo por parte de ambos os parceiros (cf. IACOBUCCI; OSTROM, 1996). Com isso, ocorre a emergência de uma nova instituição composta pelas normas, leis e demais tipificações que foram construídas socialmente por meio dessa dinâmica comunicacional, a saber: a relação per se, bem como sua identidade. Na construção desse relacionamento, os parceiros devem transmitir seus traços identitários de modo a obter o reconhecimento social do outro. Quando o consumidor gera identificação com a marca, ele sedimenta e legitima sua identidade perante a mesma, bem como a identidade dela para ele, e vice-versa. A legitimação, dessa forma, produz novos significados, os quais servem para integrar os já existentes ligados a processos díspares. A função desse legitimar consiste em tornar acessível e subjetivamente plausível as objetivações nesse caso, a identidade da relação - que foram institucionalizadas (cf. AMBLER et al, 2002; FONSÊCA, 2005; KARJALAINEN, 2003).

Para que essa dinâmica ocorra, a relação marca-consumidor tem de ser concebida como um fenômeno interpessoal; isto é, ser composta de, pelo menos, duas partes (seres humanos) distintas que interajam entre si (IACOBUCCI; OSTROM, 1996). A marca tem que ser personificada (tornar-se um "ser vivo") para o consumidor acreditar que está se relacionando com uma pessoa. Os parceiros interagem diretamente um com o outro. Por conseguinte, tal condição permite que eles se adaptem as suas demandas durante a dinâmica relacional (cf. BLACKSTON, 1993; FOURNIER; YAO, 1997). Assim, a identidade do relacionamento é construída socialmente pelos parceiros, à proporção que (por estarem em uma relação interpessoal) as interações e a comunicação entre eles ocorrem de maneira recíproca, compartilhada e mútua (cf. AMBLER et al, 2002).

\section{A identificação nos relacionamentos marca-consumidor}

No contexto das relações marca-consumidor, os parceiros geram identificação e se sentem atraídos por aqueles que lhes são similares (BLACKSTON, 1993; FOURNIER, 1994). A similaridade é um conceito bastante amplo. De fato, vários são os aspectos/características (e.g., aparência, estética, classe social, religião, nível educacional, atitudes, desejos, valores, estilos de vida e crenças) que os parceiros utilizam como "filtro" para 
escolher com quem irão iniciar, desenvolver e manter trocas relacionais (cf. AAKER,; FOURNIER; BRASEL, 2004). À proporção que as características do consumidor forem similares às da marca - e vice-versa -, podemos dizer que há uma grande possibilidade desses parceiros estabelecerem um relacionamento (duradouro). Caso não haja similaridade entre os parceiros, eles tendem a desenvolver um sentimento de repulsa em relação ao outro. Embora aceitemos que a similaridade entre os parceiros seja uma das dimensões responsáveis pelo estabelecimento do "nós", preferimos utilizar o conceito de convergência, porque, além de abarcar toda a noção de similaridade, ainda acrescenta a disposição da marca e do consumidor se dirigirem para ou se encontrarem no mesmo ponto.

Nesse sentido, a convergência é a tendência para aproximação ou união em torno de um assunto ou de um fim comum (cf. PATERSON; O’MALLEY, 2006). As similaridades/convergências entre os parceiros não são suficientes para assegurar que o relacionamento marca-consumidor seja estabelecido. Caso os parceiros não valorizem ou vislumbrem relevância nas características de cada um, a relação pode estar fadada à dissolução ou, até mesmo, nem iniciar. Apesar de parecidos, valência e relevância são conceitos distintos. A valência corresponde ao caráter atrativo ou repulsivo do objetivo, implicando assim a existência de campo de força próximo a influenciá-lo. A relevância diz respeito às propriedades do objeto valoradas por uma pessoa, mas sem o caráter de um campo de forças (DWYER, 2000; IACOBUCCI; OSTROM, 1996). Em outras palavras, podemos falar da valência de uma marca quando ela exerce influência imediata sobre o consumidor; e de relevância (e.g., atitude e valor), quando a marca tem potencialidade para influenciar os consumidores sob certas condições. Por exemplo, quando dizemos "Eu quero McDonald's", estamos sinalizando que tal marca possui valência para nós. No caso de dizermos "Eu gosto (e.g., "amo muito tudo isso") da McDonalds", estaremos indicando que a marca é relevante para nós. Assim, os consumidores atribuem a cada relação uma importância relativa, a qual pode mudar com o passar do tempo. Essa importância pode variar, entre outras coisas, de acordo com as crenças, os valores e as atitudes dos parceiros, com a natureza do relacionamento, com o histórico acumulado de interações, com a proximidade entre as partes e com o tipo e nível de benefícios extraídos da relação por cada uma das partes.

Como em todo e qualquer relacionamento, na relação marca-consumidor há também um quê emocional [afeto]. O reconhecimento constitui a parte emocional, sendo caracterizado pelo respeito social, pelo sentimento de fazer parte e pela amizade advinda da experiência de interação (HANSEN, 2000). Nesse sentido, nas relações comerciais, o consumidor sente-se reconhecido pela marca quando percebe que ela (ou seus funcionários) dispensa-lhe um tratamento especial (e.g., chamar o consumidor pelo nome, oferecer-lhe descontos e conhecer seus desejos) durante o relacionamento e vice-versa. Dessa forma, a familiaridade existente entre eles propicia a criação e o estabelecimento de vínculos de amizade entre os parceiros (cf. HENNIG-THURAU; GWINNER; GREMLER, 2002). O respeito social, conforme Bendapudi e Berry (1997), inclui os impactos e as influências (e.g., reconhecimento de status, aprovação/reprovação social) da sociedade (e.g., família e grupos de referência) no agir da marca com o consumidor e vice-versa. $\mathrm{O}$ respeito é o sentimento que leva um parceiro relacional a tratar outrem com grande atenção, com profunda deferência, consideração e reverência. Por fim, a marca seria composta não só do conjunto de características funcionais, mas também de características simbólicas a ela relacionadas. Esses símbolos (desejo) são moldados pela marca, de forma que sejam valorados e desejados por uma sociedade numa determinada época (ELLIOT; WATTANASUWAN, 1998). A intenção da marca não seria apenas refletir uma "realidade objetiva", mas também ser capaz de comunicar como os consumidores apreendem a si mesmos ou a maneira como gostariam de se aperceber (FONTENELLE, 2002). Nesse sentido, a marca pode ser encarada como uma instituição repleta de signos, um universo simbólico que comunica ao consumidor quem ela é ou pode ser para ele.

\section{Metodologia: breve visão da fenomenologia}

Para a realização deste estudo optou-se pela pesquisa qualitativa, utilizando a vertente fenomenológica, conforme sugerido por Fonsêca e Souza Neto (2007), Goulding (2005) e Kale e Shrivastava (2001). Para esses autores, recomenda-se a adoção do método fenomenológico na condução das investigações de marketing quando é necessário descrever, classificar, desvelar e compreender o que faz sentido, aquilo que se apresenta como significativo e relevante para as pessoas nas suas experiências de consumo. 
Apesar das controvérsias e dificuldades acerca do desenvolvimento, adoção e aplicação da fenomenologia nos estudos de marketing, diversos são os autores (e.g., FOURNIER, 1998; GOULDING, 2005; SEEBARANSINGH; PATTERSON; O'MALLEY, 2002; THOMPSON; HIRSCHMAN, 1995) que sugerem e utilizam os princípios fenomenológicos para compreenderem os fenômenos de marketing. A fenomenologia é um "método" puramente descritivo, o qual visa descrever os fenômenos por intermédio do estudo da significação das vivências dos indivíduos (cf. THOMPSON; LONCADER; POLLIO, 1990). Ela estuda as experiências dos parceiros relacionais e os modos como os fenômenos de marketing se apresentam per si para eles. Trata-se do estudo da essência (eidos) das coisas e dos significados articulados nos discursos e nas ações dos parceiros.

\section{Etapas analíticas do método fenomenológico}

Analiticamente, o método de pesquisa fenomenológico caracteriza-se por três etapas: descrição, redução e compreensão fenomenológica (FONSÊCA; SOUZA NETO, 2007; GOULDING; SHANKAR; ELLIOT et al, 2002; THOMPSON; HIRSCHMAN, 1995). A descrição fenomenológica é o primeiro momento da trajetória na pesquisa e resulta da relação dos entrevistados com o pesquisador, sendo, portanto, o discurso obtido, constituído de elementos estruturais do fenômeno a ser desvelado, que representa o que está articulado na inteligibilidade do entrevistado e que se mostra através da fala. A redução fenomenológica, como segundo momento da trajetória, visa determinar e selecionar as partes da descrição consideradas essenciais. Consiste, então, na busca, pelo pesquisador, das proposições que lhe são significativas e que permitem compreender aquilo que é essencial ao fenômeno em questão, a partir do discurso do entrevistado. É um procedimento planejado para retornar-se à experiência vivida pelos entrevistados, deixando de lado qualquer crença, teoria ou explicação a priori. A compreensão fenomenológica ocorre quando as expressões ingênuas do discurso são substituídas por expressões próprias do pesquisador, que representam aquilo que está sendo buscado. É um pensar sobre os significados, contemplado pela análise idiográfica e nomotética.

\section{Critérios de escolha da marca e dos entrevistados}

Optamos pela escolha da marca de fast-food McDonald's por três razões básicas:

1) é considerada um dos ícones da sociedade contemporânea e da cultura do descarte (FONTENELLE, 2002);

2) representa o melhor exemplo do processo amplamente conhecido e difundido como McDonaldização; isto é, o processo das organizações tornarem-se extremamente racionais/burocratizadas, dominadas pela eficiência, previsibilidade, calculabilidade, controle e por tecnologias não-humanas (RITZER, 2002); e por fim

3) trata-se de uma marca eminentemente relacional (FONTENELLE, 2002).

Embora a fenomenologia não estabeleça, a priori, critérios rígidos para a seleção dos entrevistados, no que se refere à escolha dos mesmos, a maioria dos estudiosos (e.g., CRESWELL, 2002; GOULDING; SHANKAR; ELLIOT et al, 2002) convergem para, pelo menos, dois pressupostos essenciais: 1) que sejam pessoas com experiência vivida do fenômeno a ser estudado e 2) que tenham capacidade de articular e externar conscientemente suas experiências acerca do vivido quanto ao fenômeno em questão.

Por conta da impossibilidade de entrevistarmos a marca per se, por ela ser um objeto inanimado que somente possui "vida" por meio dos seus pontos de contato (e.g., restaurantes, propagandas, funcionários) (cf. GRÖNROOS, 2000), optamos - seguindo as recomendações de Schön (1983) - entrevistar gerentes, por três razões: 1) relacionam-se cotidianamente com os consumidores; 2) no desempenho de suas atividades, eles refletem sobre o conhecimento estabelecido e sobre suas ações. Logo, espera-se que tenham capacidade de expressar suas experiências relacionais de vida com os consumidores; 3) por sua capacidade reflexiva, são conscientes de que (na percepção dos consumidores) personificam a marca.

O número de entrevistados foi estabelecido pelo critério de saturação das respostas das entrevistas (MILES; HUBERMAN, 1994). No total, foram realizadas cinco entrevistas válidas com gerentes da cadeia de fast-food 
McDonald's numa grande capital brasileira, no período de junho a agosto de 2006 e, posteriormente, em abril de 2007. O critério de finalização da coleta de dados consistiu na adoção do procedimento de saturação das respostas das entrevistas.

\section{Relatando os procedimentos para acessar as experiências dos entrevistados}

Nas pesquisas de cunho fenomenológico em marketing, a entrevista semi-estruturada tem sido um recurso fundamental para os pesquisadores acessarem as opiniões e experiências dos entrevistados acerca do fenômeno investigado (GOULDING; SHANKAR; ELLIOT, 2002; KALE; SHRIVASTAVA, 2001; McCRACKEN,1988). Com base nisso, é possível compreender como os entrevistados significam a identidade do relacionamento marca-consumidor. Inspirados nas recomendações de Bauer e Gaskell (2002), de Creswell (2002) e de McCracken (1988), a condução da entrevista foi realizada da seguinte forma:

1) iniciamos com as perguntas gerais e indiretas sobre o cotidiano dos entrevistados. Tais questões são chamadas de "grand-tour" e visam elucidar os propósitos da investigação, pedir permissão para gravar a sessão, demonstrar interesse, curiosidade e predisposição de ouvir a opinião dos entrevistados, além de construir uma atmosfera de confiança e de informalidade, a fim de deixá-los a vontade para discursar livremente sobre o fenômeno investigado;

2) realizada essa etapa, iniciamos a entrevista propriamente dita, com o suporte e uso de um protocolo de pesquisa, cuja pergunta básica era: Qual o significado desse relacionamento para você? Além desta, nos diálogos surgiram outras questões reflexivas decorrente dessa inicial, tais como:

- Fale-me sobre o que lhe conduziu a esta carreira;

- Como você descreveria o seu relacionamento com o seu consumidor?

- Fale-me sobre o que está contribuindo; isto é, se algo está contribuindo para você se relacionar com o seu consumidor;

- O que os seus consumidores só fazem com você?

- Você se identifica com o seu consumidor?

O protocolo dessa investigação foi construído com base nas orientações de McCracken (1988) e de Creswell (2002). Essas perguntas, geradas subseqüentemente, entre outras, permitiram um conhecimento aprofundado dos significados da identidade do relacionamento marca-consumidor. Nessa etapa, os entrevistados discorreram, de forma oral e livre, sobre elementos de sua vivência cotidiana, manifestando suas percepções quanto a aspectos relacionados ao fenômeno em questão. Desse modo, foi possível identificar elementos de regularidade seja em ações muitas vezes relembradas como positivas, seja em ações tidas como erros. Vale ressaltar que na disposição das questões básicas do protocolo de investigação, ocorreram sutis intervenções quando os relatos nos direcionavam para discussões que fugiam ao interesse da pesquisa ou quando manifestavam expressões e conceitos que demandavam esclarecimentos, os quais, por sua vez, redundavam em outras questões mais aprofundadas. Além disso, elaboramos anotações de perguntas para nos orientar na interação com os gerentes, quanto à práxis, à reflexão e ao diálogo. Para realizar o tratamento dessas concepções recorremos à discussão de Bicudo (2000).

\section{Procedimentos adotados para a consecução das análises}

A análise do conteúdo das entrevistas seguiu o princípio da redução fenomenológica, sugerido por Bicudo (2000), adotando-se os procedimentos descritos a seguir.

No plano idiográfico, procedeu-se à leitura atenta das descrições de cada um dos entrevistados, para que se tivesse uma visão ampla dos conteúdos narrados. Vale salientar que as descrições foram lidas na íntegra, várias vezes, para que pudéssemos nos familiarizar com os textos que descrevem a experiência vivida. Em seguida, essa leitura focou as unidades de significados, ou seja, as expressões que revelassem claramente a percepção dos gerentes sobre o que está sendo pesquisado, segundo suas próprias palavras. Cada entrevista foi 
fragmentada nessas unidades de significado, considerando-se que estas representam pólos em tornos dos quais se aglutinam os sentidos manifestos nas experiências dos gerentes, segundo o foco peculiar considerado pelo pesquisador a partir das interrogações que formulou. Assim, embora encerrem a discussão de uma idéia ou tópico geral, cada uma dessas unidades permite a constante retomada de sentido.

Uma vez delimitadas, as unidades de significado foram codificadas da seguinte forma: o parêntese (4.2) corresponde, por exemplo, ao segundo núcleo de significado presente no relato do quarto gerente. As unidades de significado ainda possuem a seguinte legenda: P corresponde à fala do pesquisador; $G$ representa o relato do gerente. Para cada entrevistado, as unidades de significados foram captadas e registradas em quadros contendo inicialmente três colunas, uma para o trecho da transcrição referente à fala dos entrevistados, outra para a compreensão do pesquisador (transformar essas descrições em um discurso estruturado) e uma última para relevância (as articulações da experiência ou situação descrita). Após esse procedimento, uma quarta coluna foi aberta, onde o pesquisador, com base nas teorias de identidade em marketing de relacionamento, buscou compreender (e categorizar) as temáticas subjacentes (metatemas), na intenção de revelar a essência. O quadro 1, por exemplo, apresenta um movimento de redução em que às sínteses das unidades de significado se transformam em essências.

\section{Quadro 1 - Ilustração das etapas da análise idiográfica}

\begin{tabular}{llll}
\hline Trecho & Compreensão & Relevância & Metatemas \\
\hline (1.34) G: [...] Agora a gente está tendo o seguinte & Ao “cantar a musiquinha do & O consumidor & Identificação \\
projeto: o cliente que cantar a musiquinha do & BigMac", o gerente está & identifica-se & Relevância \\
BigMac, ganha o sanduíche. Isso é relacionamento & consciente de que o & com a marca e a & Valência \\
com o cliente. [...] Você identifica o cliente como & consumidor se identifica com a & valora. & Marca-signo \\
aquele cara que consegue cantar. [...] ganhar o big & $\begin{array}{l}\text { marca e valoriza os artefatos } \\
\text { dela. }\end{array}$ & & \\
mac é um negócio vantajoso não é? & & & \\
& & & \\
\hline
\end{tabular}

Fonte: adaptado de Fonsêca e Souza Neto (2007)

$\mathrm{Na}$ análise nomotética, lidamos com os dados advindos da análise idiográfica, ou seja, da análise do individual, indicando com isso um movimento de passagem do individual para o geral. O fim a que se deseja chegar é a estrutura geral, estrutura que resulta da compreensão das convergências e das divergências que se mostram a partir das significações individuais. A estrutura psicológica geral pode, como um todo (pelo menos, em princípio), pertencer a vários outros indivíduos (BICUDO, 2000). As análises nomotéticas tiveram início com a aglutinação, em um mesmo quadro, de todos os itens reduzidos que, ao longo de todas as entrevistas, receberam o mesmo "rótulo" temático, explicitando nosso pensar acerca dos significados essenciais para dar conta da compreensão sobre os sentidos atribuídos aos princípios identitários presentes no relacionamento marcaconsumidor. Tal processo pode ser observado no quadro 2.

\section{Quadro 2 - Ilustração da etapa da analise nomotética}

\begin{tabular}{llll}
\hline Referência & $\begin{array}{l}\text { Significados } \\
\text { Estruturais }\end{array}$ & Código & $\begin{array}{l}\text { Número De } \\
\text { Essências }\end{array}$ \\
\hline $\begin{array}{l}\text { Construto } \\
\text { identidade }\end{array}$ & Identidade & & \\
\hline & & $(2.7)(2.10)(2.12)(2.3)(3.17)(3.9)(4.9)(4.13)(4.12)$ \\
& & $(4.13)(4.14)(5.15)(5.18)(1.13)(1.14)(1.15)(1.33)$ & 27 \\
& Identificação & $(1.37)(1.15)(1.16)(1.18)(1.19)(1.1)(1.24)(1.34)$ & \\
& & $(5.19)(5.14)$ & \\
\hline
\end{tabular}

Fonte: adaptado de Fonsêca e Souza Neto (2007)

A partir desse procedimento - e com o retorno simultâneo à passagem original de onde cada item reduzido foi extraído -, pudemos realizar comparações analíticas que nos possibilitaram compreender tanto as principais 
formas pelas quais a temática se substancializa (e pode se substancializar) nos relatos dos gerentes, quanto os conteúdos a que estão associados. Em torno dessas categorias, formulamos interpretações articuladas com as unidades de significados, com as análises já feitas, com as interrogações, com os autores lidos, com os depoimentos e com a nossa reflexão.

\section{Critérios de qualidade e consistência em pesquisas qualitativas}

No ímpeto de alcançarmos a qualidade e a consistência requeridas pelas pesquisas qualitativas, para efeitos deste artigo, seguimos os procedimentos sugeridos por Miles e Huberman (1994), a saber: notas de campos, triangulação, auditor de pesquisa, member check, construção de corpus de pesquisa e descrição detalhada.

As notas de campo constituíram-se a partir dos registros das observações que realizamos, principalmente, acerca das manifestações verbais e não-verbais dos entrevistados. Vale salientar que tivemos a preocupação de registrar tanto as nossas observações (sobre o local da pesquisa, as mudanças de perspectiva do entrevistado e os esclarecimentos, por exemplo) quanto os fatos verificados na sequiência em que ocorreram. As anotações foram realizadas durante e após as entrevistas.

Outra forma de garantir confiabilidade aos dados desta investigação foi pela triangulação das distintas fontes de informação (CRESWELL, 2002). Esse procedimento foi importante para evidenciarmos as inconsistências/consistências, discrepâncias e discordâncias/concordâncias presentes nos discursos dos entrevistados sobre o fenômeno investigado.

Para evitar vieses de interpretação provenientes dos relatos, solicitamos exaustivamente aos entrevistados que explicassem melhor pontos contraditórios, para elucidarmos melhor suas idéias. Alguns deles tiveram de ser acessados mais de uma vez, para que fossem esclarecidos pontos obscuros de seu discurso; etapa essa, de validação do fenômeno através do respondente conhecida como member check. Tal validação não ocorreu somente durante as entrevistas, mas também após a sua transcrição.

Além disso, disponibilizamos as transcrições das entrevistas aos gerentes para que nos indicassem/confirmassem se estas realmente refletiam aquilo que eles pretenderam nos dizer. Para conferir credibilidade à pesquisa, foi alocada uma pessoa distinta (no caso desta investigação, um professor doutor), juntamente com o pesquisador, para acompanhar e participar (elaborando e fazendo perguntas as perguntas) das entrevistas. Ademais, foi mobilizado um auditor externo (external auditor) para acompanhar, principalmente, o processo de análise dos dados e a etapa das reflexões conclusivas.

Com base na transcrição das entrevistas foi construído um corpus de pesquisa, o qual serviu para consecução da análise dos dados. Conforme Brown (2002), o corpus é compreendido como uma coleção finita de materiais (i.e., textos, imagens, músicas ou outros materiais) determinada de antemão pelo pesquisador, com (inevitável) arbitrariedade - e com a qual ele irá trabalhar -, devendo ser compativel com os objetivos da pesquisa. A construção do corpus é critério tanto de confiabilidade quanto de validade nas pesquisas sociais, posto que, visa maximizar a variedade e de representações desconhecidas. O corpus equivale funcionalmente a uma amostra representativa dos estudos quantitativos (BAUER; AARTS, 2002).

Outro ponto de destaque foi o uso extenso de registros literais de fontes, denominado de descrição detalhada (BAUER; GASKELL, 2002). Cabe, portanto, ao pesquisador proporcionar suficiente descrição do contexto sociohistórico do cenário da pesquisa e dos indivíduos analisados, para que os leitores fiquem aptos a determinar a proximidade de suas situações com o cenário relatado na pesquisa e, até, se as descobertas podem ser transferíveis. Dessa forma, todas as unidades de significados consistiram de longos extratos literais do discurso dos gerentes acerca de suas experiências, atitudes, hábitos, credos e pensamentos. Por fim, foi descrita detalhadamente a contextualização de eventos, pessoas, interações e observações de comportamento dos entrevistados. 


\section{"Análise dos resultados": a identidade da relação marca-consumidor}

Concluída a redução fenomenológica, verificamos que as estruturas constituintes da identidade do relacionamento marca-consumidor são: a) identificação resultante da sinergia entre convergência, valência/relevância, signo e a "casa"; e b) o reconhecimento.

\section{Identificação e convergência no relacionamento marca-consumidor}

O relacionamento marca-consumidor só existe a partir de uma identificação mútua entre os parceiros. Para o gerente, a entrega do padrão da marca (i.e., QSLV) ${ }^{2}$ e as ações de cidadania (e.g.; "McDia Feliz") são formas do consumidor "vestir a camisa" (comprometimento), acreditar (confiança), ser, ir, gostar, incorporar, ajudar (cooperação) e identificar-se com essa marca. Tal identificação é tamanha, que o consumidor chegar a querer os artefatos (e.g., camisas) que a representam e, com isso, sinaliza que deseja incorporar-se (i.e., fazer-se existir) à marca e ao "nós". Desse modo, a convergência dos parceiros é notória, no momento em que se esforçam para chegar a um ponto em comum, auxiliar o NACC, ${ }^{3}$ que têm a mesma opinião quanto ao padrão da marca (e.g., segura, confiável e transparente) e se declaram parte da mesma comunidade de marca (e.g., "eu também sou McDonald's"). Esse argumento é aqui destacado:

G: [...] o Mcdia feliz é um evento institucional, mas que também faz com que as pessoas vistam a camisa, "eu também sou McDonalds". Elas querem dizer que estão juntas com o McDonald's para ajudar, [...]. A forma que eu vejo dos clientes se identificarem com o McDonald's é quando tem o McDia feliz, que é onde eles podem comprar a camisa com o logotipo, além de estar ajudando o NACC. [...]. Eles ficam vinculados ao "eu também sou McDonald's! (4.13)

Ao vislumbrar o relacionamento como uma "troca de felicidades", o gerente ressalta a importância de "satisfazer" e propiciar o bem-estar dos consumidores. Para ele, essas ações os deixam empolgados com a relação e a marca, ampliando o retorno e garantindo maior assiduidade. Ademais, para despertar nos consumidores identificação e confiança na marca - a ponto da "família retornar ao McDonald's" - o gerente deve proporcionar-lhes uma convivência agradável com ela, reconhecendo esse consumidor como uma pessoa e fazendo com que ele se sinta a vontade no "nós", consoante estes trechos destacados:

G: Enfim, eu fico satisfeito, [...], eu gosto de atender pessoas, eu fico feliz quando a pessoa se sente feliz. Eu acho que é até um negócio promissor [...], você vai estar feliz onde é atendido bem, [...]. Então, ele começa a se identificar onde vai se sentir bem. É isso que a gente busca sempre. (1.15)

G: Acho que a satisfação dele. Eles têm retornado mais ao McDonald's, a família está retornando, [...] então, isso é agradável para o McDonald's. [...] Olha, torna-se importante na hora quando ele chega ao balcão e, ao atendê-lo, ele está bem satisfeito, bem empolgado, ou até mesmo a convivência dele dentro do Mcdonalds ser constante, uma convivência assídua. (2.10)

Para alavancar a identificação dos consumidores com a marca, em alguns casos (principalmente, com os consumidores mais assíduos), o gerente é capaz de romper com o QSLV, entregando "algo mais" (e.g.; com a realização de uma festa surpresa) quando pretende enfatizar laços de intimidade na relação. Na percepção dele, isso é uma heresia, pois nos treinamentos fora-lhe ensinado que o padrão deve ser rigorosamente seguido com todos os clientes (5.18). No entanto, com um "jeitinho", foge desse padrão (e.g.; ao colocar maionese no BicMac ou adicionar mais MMs ao sundae) para que o consumidor perceba que o relacionamento com a marca é permeado de confiança, satisfação, segurança e afeto (3.5). Tais ações podem ser exemplificadas a seguir:

G: [...] a gente tem uma cliente, o nome dela é Cristiane, ela é louca por isso aqui. Ela só compra aqui no McDonald's, porque a McDonald's, em si, tem o atendimento muito diferenciado das outras, dos outros restaurantes, [...], tanto é que a cliente adora comprar aqui, porque no dia do aniversário dela, a gente [a] colocou aqui no salão, deu um sundae para ela, tiramos fotos com ela, e ela ficou surpresa. Ela tem a nossa cara, a cara do McDonald's, e agora ela só vem aqui.(1.33) 


\section{Valência e relevância no relacionamento marca-consumidor}

Ao cantar o jingle do BicMac, o consumidor demonstra identificação com a marca e desejo de se engajar no relacionamento. Vale ressaltar que nem todos os consumidores são capazes (i.e., alguns não sabem cantar a música) ou estão dispostos a realizar esse ato (i.e., por vergonha). Por conta disso, esse tipo de ação por parte dos consumidores deve ser valorizada, pois sinaliza o desejo (uma valência) e um esforço para conquistar os artefatos da marca (i.e., BicMac). Corroborando esse argumento, segue um trecho extraído do discurso do gerente:

G: [...] Agora, a gente está tendo o seguinte projeto: o cliente que cantar a "musiquinha" do BigMac, ganha o sanduíche. Isso é relacionamento com o cliente. [...] Você identifica o cliente como aquele cara que consegue cantar. [...] ganhar o BigMac é um negócio vantajoso, não é? (1.34)

$\mathrm{Na}$ visão do gerente, o retorno dos consumidores e a sua assiduidade com a marca podem ser compreendidos como ações que eles desempenham no intuito de sinalizar a valência que a marca e o "nós" possuem para eles (2.10). Isso é tão importante para o processo de identificação nesse relacionamento, que o gerente reconhece a necessidade de estar mantendo e aprimorando continuamente a entrega do padrão, como forma de intensificar a relação. Tal argumento está exposto a seguir:

G. se [o cliente] volta é porque foi bem atendido. Ele gostou da comida. Ele retornou porque a gente deu um bom atendimento, deu um sanduíche com qualidade. Caso ele não volte, é porque ele não gostou do atendimento ou da comida! (3.14)

Ao qualificar o consumidor de "espião/patrão", o gerente aponta que valora as opiniões, reclamações, referências e direcionamentos provenientes daquele, com a finalidade de promover o aperfeiçoamento da instituição relacional e da marca. Na percepção do gerente, a existência de fortes laços de intimidade no "nós" faz com que essas elocuções do consumidor sejam tidas como diretrizes seguras e confiáveis. Dessa forma, a marca identifica-se com o consumidor "espião" quando conscientemente percebe que ambos convergem para um mesmo fim, ou seja, construir um "nós" permeado de bem-estar. Isso pode ser observado no extrato da fala do sujeito a seguir:

G: Tem uma senhora, o nome dela é dona $K$, [que] passou a ser para mim [...] um tipo de segurança. Um dia desses, a pista do drive estava cheia de buracos, ela passou e disse: "Oh fulano, vou te falar uma coisa, acho que é bom dá uma melhoradazinha naquele buraco ali da pista drive, porque já está começando a afetar seus clientes!". Eu disse: "se está afetando a senhora, está afetando realmente meus clientes!". Ela me deu o toque, com três dias eu mandei ajeitar ali e, pronto; quatro dias depois, ela chegou aqui e disse: "ficou beleza!" (4.9)

Na percepção do gerente, o consumidor valoriza a marca e a manutenção do relacionamento no momento em que se identifica, respeita e coopera com as ações de cidadania patrocinadas por ela (4.13). Além disso, a marca possui relevância para os consumidores, à medida que eles percebem a aprovação e o status social derivados do relacionar-se com a marca (4.12).

\section{$O$ valor do signo no relacionamento marca-consumidor}

O gerente conscientiza-se de que os valores semânticos da marca-signo desempenham um papel fundamental na construção e no desenvolvimento dos laços relacionais. A marca comunica aos consumidores uma série de significações, as quais os levam a reconhecer a identidade dela e a acreditar (confiar) nas suas promessas. Por exemplo, os "arcos dourados" tendem a ser percebidos pelo consumidor como sinônimo de qualidade, de segurança e de confiança, posto que ao visualizar esses "arcos", não importa onde eles estejam, os consumidores têm a certeza de que a marca entregará o padrão "QSLV" de forma homogênea, segura e esperada. Ademais, a marca-signo representa status e prestígio social. Nesse sentido, diferentemente dos signos concorrentes, o McDonald's é percebido pelo consumidor como um signo que confere (por intermédio do prestígio social que ele emana) o passaporte para o consumo elitizado. Essa idéia pode ser encontrada no trecho destacado: 
G: [...] Acho que ele se identifica mais com a imagem do McDonald's, do ambiente, do restaurante e do lugar. Teoricamente, é bom ficar; como tem muita gente que senta aqui, "Ó, tô no McDonald's, vem pra cá!”, “Ó, tô no Mcdonald's!”. Então, muitas pessoas vêm para cá e ficam comentando, que estão em um lugar de alto nível, assim, como se fosse coisa de elite. E, até certo ponto é de elite, por causa da qualidade, embora o McDonald's não queira ser apenas percebido como algo de elite; ela quer ser todos os consumidores. [...] Hoje, eles se identificam com um diferencial, uma coisa elitizada, [...] "eu tô aqui no McDonald's!". Há status em estar no McDonald's, [...] pela qualidade. O cara vai estar lá no Rio de Janeiro, em Belo Horizonte, seja onde estiver, lá estará um arco dourado McDonald's. O cara vai entrar para comer, porque ele sabe que é igual ao que ele está pedindo, ele tem essa percepção, sim, de segurança Ele se sente seguro. (4.12)

\section{A emergência da "casa" no relacionamento marca-consumidor}

Como em uma família, a marca "mãe" objetiva seu comprometimento em "cuidar" dos seus "entes queridos" (i.e., consumidores) que vêm "visitá-la" de tempo em tempo (2.13) (3.8). Esse "ato de cuidar" reflete a preocupação dela em propiciar ao "consumidor convidado" experiências (e.g., brincadeiras, ambiente agradável e descontraído, "padrão" da marca, "tratar bem", sorrisos e chamá-lo pelo nome) que o façam perceber que o "espaço relacional" da McDonald's é um ambiente caseiro, sua "segunda casa". A casa é um espaço social onde o consumidor pode sentir-se à vontade, confortável, seguro, íntimo, familiar, reconhecido e consciente da previsibilidade relacional, características que aumentam sua identificação com a "marca-casa", conforme observado a seguir:

\section{P: O que você faz pelo seu consumidor?}

G: Tudo para satisfazê-lo. Do bom atendimento, do bom sorriso, de uma boa conversa, de uma boa qualidade de produto, de uma boa limpeza, de um ambiente agradável, a decoração, um menu bem iluminado, um ar-condicionado, um som ambiente, um sorriso de um funcionário, um bom-dia realmente espontâneo, um "volte sempre" espontâneo. Eu faço tudo para satisfação de meu cliente. [...] A gente trabalha muito focado no QSLV [...] [É] muito importante a gente não deixar que nada afete o pensamento do cliente, para incentivar o uso da marca McDonald's. Então, tudo afeta o cliente. Até simplesmente [com] um móvel, o cliente se identifica. Porque ele vai se sentir num lugar realmente agradável, um ambiente realmente limpo. Muitos deles, com certeza, sentem-se em casa, e esse é o objetivo da gente do McDonald's: que o cliente se sinta confortável, que ele se sinta em casa! A casa é um lugar onde ele possa estar de bem com a vida, estar confortável, que ele realmente se identifique. Se identifique... (2.7)

\section{Reconhecimento na relação marca-consumidor}

Ao proporcionar as experiências do sentir-se em "casa", o gerente visa construir uma ambiência relacional onde o consumidor se reconheça como membro de uma "família" (3.8). Por conta dos laços de intimidade nesse espaço, os consumidores serão reconhecidos pelo nome e o gerente conhecerá as demandas e necessidades deles, por exemplo. Ao valorar e respeitar as manifestações (e.g., opiniões, diretrizes, reclamações e direcionamentos) dos consumidores "espiões" (que visam alavancar o "nós"), o gerente reconhece que eles são pessoas confiáveis e seguras, a ponto de ouvir e seguir seus "conselhos" (4.9). O gerente (logo, a marca) sentese reconhecido pelos consumidores, à proporção que:

- eles elogiam o trabalho bem realizado dos funcionários (e.g., objetivar $100 \%$ do padrão, o bom atendimento);

- identificam-se com as ações de cidadania promovidas por ela;

- desejam incorporar-se nela e no relacionamento; e

- querem possuir os artefatos dela. 
A sensação de reconhecimento deriva também da aprovação social dos amigos e da família, por exemplo, e do "status" que o consumidor adquire por estar imbricado em tal relacionamento.

\section{Respeito no relacionamento marca-consumidor}

No relacionamento em questão, o respeito surge à medida que os parceiros se tratam com grande consideração e deferência. $\mathrm{O}$ consumidor manifesta esse sentimento em relação à marca no momento em que a qualifica como "marca-signo". A reputação mundial e o QSLV são exemplos de sinalizações que a marca possui para conquista o respeito do consumidor. Esses sinais influenciam a maneira como este percebe a marca, a ponto de considerá-la confiável, uma vez que transmite segurança. Portanto, visando ser respeitada pelo consumidor, a marca é cônscia de que deve realizar suas ações (i.e., investir na entrega "correta" do padrão, promover a cidadania, proporcionar a diafaneidade relacional, garantir o "bom atendimento") para que o consumidor atribua um "justo valor" não apenas a ela, mas também ao "nós". Por sua vez, a marca respeita e valoriza o consumidor nesse relacionamento quando se preocupa em satisfazer suas necessidades e atender aos seus desejos, objetivando um retorno por parte dele. Esse argumento é exemplificado nesta transcrição.

G: O McDonald's é a marca! É uma potência mundial. Pensou em McDonald's, as pessoas falam o seguinte: "Ah! McDonald's é confiável”. Então, o consumidor respeita muito a marca, confia muito na marca, até mesmo por a gente passar uma segurança para eles. Eu volto novamente ao assunto: segurança de qualidade, de serviços e de limpeza são nossas metas. A gente trabalha constantemente, diariamente, essa meta: satisfação total do cliente, em qualidade, serviços e limpeza.

$$
\begin{aligned}
& \text { P: É o QSLV? } \\
& \text { G: É o QSLV (2.6) }
\end{aligned}
$$

\section{Considerações finais}

[Re]Construir e comunicar determinada(s) identidade(s) (por intermédio de sinais, artefatos, sinalizações, mídias, cenários de serviços e funcionários, por exemplo) são algumas das premissas básicas, para que os parceiros decidam (ou não) iniciar uma relação. Desse enfoque, a compreensão do relacionamento marcaconsumidor sinaliza que: o ato de relacionar-se depende muitas vezes dos consumidores identificarem-se, reconhecerem e respeitarem (mutuamente) os traços, as características, a subjetividade, as ações e o estilo, por exemplo, comunicados pela marca e vice-versa.

A identidade do relacionamento em questão é [re]construída e estabelecida à proporção que os parceiros percebem:

- que existem convergências e similaridades entre suas identidades, bem como entre estas e a do "nós";

- que o espaço da "casa" permeia a relação;

- que suas ações são valorizadas; e

- as objetivações semânticas da "marca-signo".

Todavia, essas pistas e direcionamentos acerca da identidade da relação não são suficientes para que os parceiros se identifiquem com ela, a ponto de quererem estabelecer um relacionamento. Embora o processo de identificação tenha inicio quando os parceiros percebem a identidade que lhes está sendo comunicada, é necessário que reconheçam e respeitem essa identidade, bem como se sintam reconhecidos e respeitados por ela. Tais aspectos são tidos como formas de proporcionar a emergência e de cultivar a longevidade da relação. Assim, como podemos observar, o entendimento desse fenômeno extrapola a concepção de construção de identidade proposta por Blackston (1993) e Keller (2002), por exemplo, pois a identificação ocorre de forma compartilhada e conjunta pelos parceiros.

É sabido que a identidade dessa relação não é constituída num vácuo cultural e moral, portanto, a linha pontilhada do retângulo (que representa a totalidade da identidade do relacionamento marca-consumidor) 
indica que a identidade não é fechada em si mesma, porque existem outros fatores (e.g., contexto, aprendizagem, moral, confiança e afeto), cuja influência impacta a maneira como os parceiros percebem, aceitam/rejeitam ou modificam a identidade (ver MELLO; FONSÊCA, 2007; SOUZA NETO; MELLO, 2007).

Diante do exposto, podemos suscitar que a identificação entre marca e consumidor pode ser formalmente estruturada conforme a figura 1 , mostrada adiante.

É plausível que a compreensão gerada acerca do relacionamento marca-consumidor esclareça que a construção da instituição (i.e., identidade da relação) depende dos parceiros se identificarem uns com os outros, como também com o "nós". Contudo, como podemos observar, a compreensão desse fenômeno extrapola a concepção de construção de identidade proposta por Blackston (1993) e Keller (2002), por exemplo, pois a identificação ocorre de forma compartilhada e conjunta pelos parceiros. $\mathrm{O}$ ato de relacionar-se depende da marca e do consumidor identificarem-se mutuamente com as características um do outro e com a identidade do "nós".

A objetivação do padrão QSLV e das ações de cidadania são meios que a marca possui para o consumidor se identificar com ela, a ponto de almejar "incorporar-se" à relação. A previsibilidade do "nós" contribui para a identificação, à proporção que auxilia os parceiros a preverem as demandas alheias, podendo antecipar-se a elas, com vistas a satifazer suas necessidades. Todavia, nem sempre a identificação ocorre devido à apologia do padrão da marca. Na verdade, em algumas circunstâncias faz-se necessário que os parceiros rompam com as normas do QSLV e do "nós", ofertanto o "algo mais", com vistas a manter o relacionamento marcaconsumidor. Ademais, a identificação emerge à medida que as necessidades são satisfeitas, que a convivência é assídua, que há o retorno da família ["nós"] e que existe confiança nessa relação. Corroboramos os estudos de Fournier (1994) e de Dwyer (2000) no que tange a similaridade, pois, de fato, essa propriedade relacional depende em parte dos parceiros convergirem quanto as suas percepções sobre as normas e padrões da marca, assim como em relação aos valores, às atitudes e às ações que visem ajudar outrem (e.g., exercício da cidadania).

Ao perceber os consumidores como a razão de ser do relacionamento, o gerente aponta a valência deles na construção do "nós". Assim, as referências e as opiniões do consumidor - cujo fim é promover o aperfeiçoamento da marca e da relação - são percebidas pelo gerente como direcionamentos valorosos para que ele mantenha, modifique ou aprimore a entrega do QSLV. O retorno à marca e a convivência assídua, por exemplo, são ações dos consumidores, as quais indicam ao gerente que eles valorizam o "estar engajado" na relação. É por intermédio desse relacionamento que eles conseguem satisfazer seus desejos. A marca-signo desempenha um papel fundamental na construção e no desenvolvimento da identidade do "nós", pois os signos (valor semântico/significações) desta são utilizados como vetores (direcionam e dão sentido), ou melhor, pistas. Essas pistas, por sua vez, fornecem aos consumidores subsídios para se conscientizarem das normas e do padrão da marca - reconhecendo-a e nela confiando (logo, confiando nas suas ações) -, do status e do prestígio social (que lhes abrem as portas do consumo elitizado), gerando previsibilidade, por exemplo, que propicia o fortalecimento dos laços relacionais. 


\section{Figura 1 - O processo de identificação entre marca e consumidor}

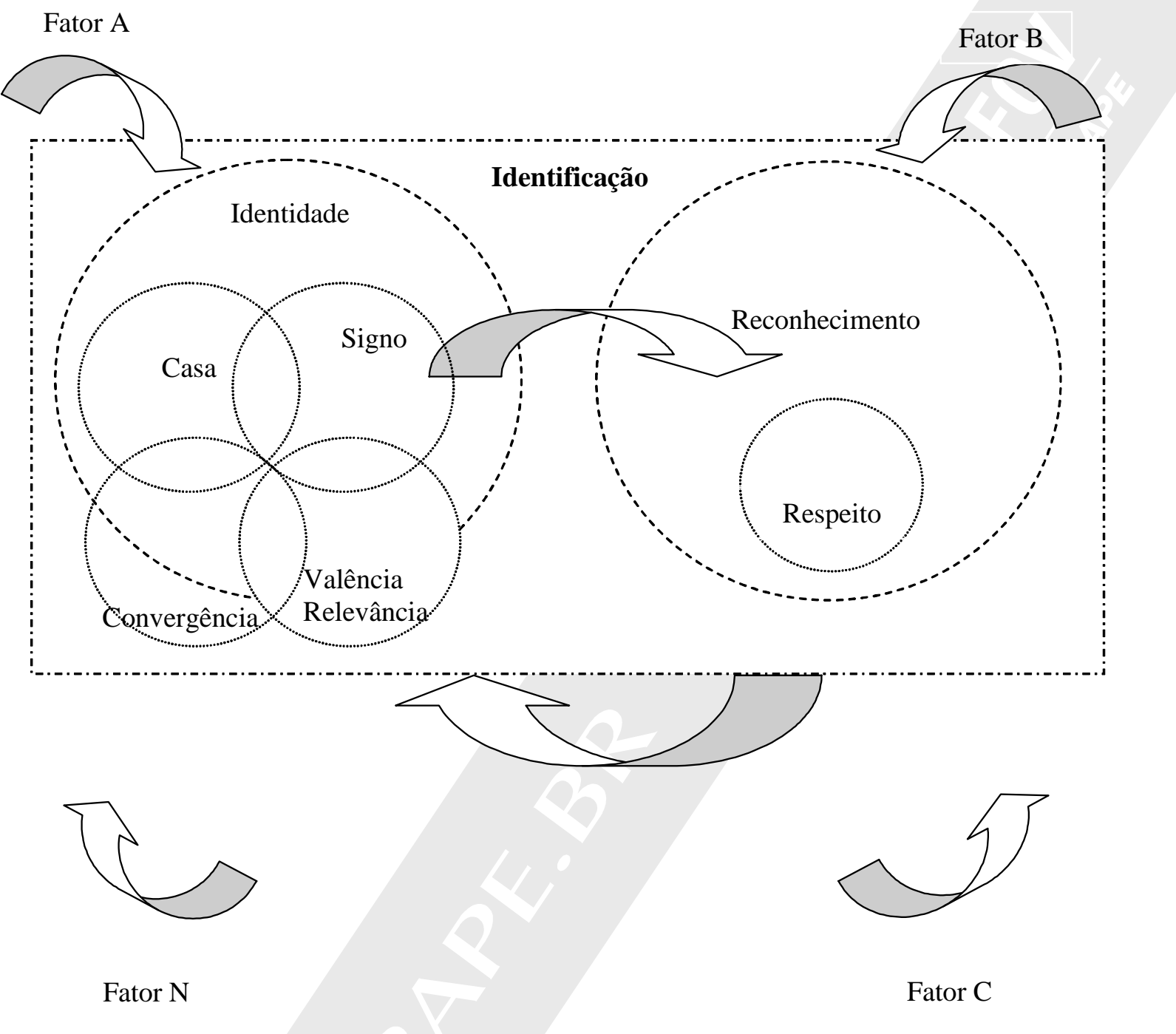

Fonte: os autores (2008)

Ao construir a identidade do relacionamento marca-consumidor como "a casa", a marca objetiva para si e para o consumidor um "espaço" ["nós"] permeado pelas relações de afeto, familiaridade, amizade, segurança, hospitalidade, confiança, reciprocidade, comprometimento, transparência e cooperação entre os parceiros. Na "marca-casa", os consumidores sentem-se reconhecidos, à vontade, confortáveis e íntimos. Portanto, essa identidade de "casa" fortifica e desenvolve os laços relacionais do "nós", fazendo com que os parceiros vejam a relação como um "ambiente caseiro". O reconhecimento e o respeito desempenham um papel importante ao destacar os laços de intimidade nesse relacionamento. Conhecer os consumidores pelo nome, realizar as melhorias que os consumidores propõem à marca, ter o exercício da função reconhecido e obter prestígio social por estar nesse relacionamento, por exemplo, são algumas das formas pelas quais essas dimensões relacionais se manifestaram nesse "nós". 


\section{Referências}

AAKER, D. A.; FOURNIER, S.; BRASEL, S. A. When good brands do bad. Journal of Consumer Research, v. 31, p. 1-16, 2004.

AGGARWAL, P.; LAW, S. Role of relationship norms in processing brand information. Journal of Consumer Research, v.32, p.453-464, 2005.

AMBLER, T.; BHATTACHARYA, C. B.; EDELL, J.; KLLER, K. L.; LEMON, K. N.; MITTAL, V. . Relating brand and customer perspectives on marketing management. Journal of Service Research, v. 5, n. 1, p.13-25, 2002.

BARBOSA, L.; CAMPBELL, C. 0 estudo do consumo nas ciências sociais contemporâneas. In: BARBOSA, L.; CAMPBELL, C. (Org.). Cultura, consumo e identidade. Rio de Janeiro: Editora FGV, 2006.

BAUER, M. W.; AARTS, B. A construção do corpus: um principio para a coleta de dados qualitativos. In: GASKELL, G. (Ed.).

Pesquisa qualitativa com texto, imagem e som: um manual prático. Tradução: Pedrinho A. Guareschi. Petrópolis: Vozes, 2002.

; GASKELL, G. Pesquisa qualitativa com texto, imagem e som: um manual prático. Rio de Janeiro: Vozes, 2002.

BENDAPUDI, N.; BERRY, L. Customers' Motivations for Maintaining Relationships with Services Providers. Journal of Retailing, v.73, p.1537, 1997.

BENGTSSON, A. Towards a critique of brand relationships. Advances in Consumer Research, v. 30, p. 154-158, 2003.

BICUDO, M. A. V. Fenomenologia: confrontos e avanços. Cortez: São Paulo, 2000.

BLACKSTON, M. Observations: building brand equity by managing the brand's relationships. Journal of Advertising Research, v. 32, n. 3, p.79-83, 1992.

Beyond brand personality: building brand relationships. In: AAKER, D. A.; BIEL, A. L. Brand equity \& advertising's role in building strong brands. New Jersey: Lawrence Erlbaum Associates, 1993.

BROWN, S. Vote, vote, vote for Philip Kotler. European Journal of Marketing, v. 36, n.3, p. 313-324, 2002.

CRESWELL, J. W. Research design: qualitative, quantitative and mixed methods approaches. 2.ed. Thousand Oaks: Sage, 2002.

DALL'OLMO REILLY, F.; DE CHERNATONY, L. The service brand as relationship builder. British Journal of Management, v. 11, n. 2, p. 137$150,2000$.

DeCHERNATONY, L. Brand management through narrowing the gap between brand identity and brand reputation. Journal of Marketing Management, v. 15, p.157-79, 1999.

DWYER, D. Interpersonal relationships. London: Routledge, 2000.

ELLIOT, R.; WATTANASUWAN, K. Brand as symbolic resources for the construction of identity. International Journal of Advertising, v. 17, n. 2, p. 131-145, 1998.

FONSÊCA, F. R. B. [Re]Compreendendo o relacionamento marca-consumidor: um novo arcabouço conceitual para clarificar o fenômeno. In: ENCONTRO DE MARKETING, 2., 2006, Rio de Janeiro, RJ. Anais... Rio de Janeiro: EMA, 2006.

; MELLO, S. C. B. Clarificando a identidade do fenômeno relacional marca-consumidor: uma visão proveniente da antropologia social ou eu vou, eu vou para a McDonalds, agora eu vou... In: ENCONTRO DA ASSOCIAÇÃO DE PÓS-GRADUANDOS EM ADMINISTRAÇÃO, 29, 2005, Brasilia, DF. Anais... Rio de Janeiro: Anpad, 2005. CD-ROM, MKT-A 792.

; SOUZA NETO, A. F. A ética em marketing aplicada no relacionamento marca-consumidor. In: ENCONTRO DA ASSOCIAÇÃO DE PÓS-GRADUANDOS EM ADMINISTRAÇÃO, 31, 2007, Rio de Janeiro, RJ. Anais.... Rio de Janeiro: Anpad, 2007.

FONTENELLE, I. A. 0 nome da marca: McDonalds, fetichismo e cultura descartável. São Paulo: Boitempo Editorial, 2002.

FOURNIER, S. A. Consumer-brand relationship framework for strategic brand management, Ph.D. Dissertation, University of Florida, 1994. 
Consumer and their brands: developing relationship theory in consumer research. Journal of Consumer Research, v.24, n.4, p.343-373, 1998.

; SENSIPER, S.; McALEXANDER, J.; SCHOUTEN, J. Building brand community on the Harley Davidson posse ride. Harvard Business School, 2001.

; YAO, J. L. Reviving brand loyalty: a reconceptualization with in the framework of consumer-brand relationships. International Journal of Research in Marketing, v.14, n. 5, p.451-472, 1997.

GOULDING, C. Grounded Theory, ethnography and phenomenology: a comparative analysis of three qualitative strategies for marketing research. European Journal of Marketing, v. 39, n. 3-4, p. 294-308, 2005.

; SHANKAR, A.; ELLIOT, R. Working weeks, rave weekends: identity fragmentation and the emergence of new communities. Consumption, Markets and Culture, v. 5, n. 4, p. 261-284, 2002.

GRÖNROOS, C. Service management and marketing: a customer relationship approach. 2.ed. Chischester: John Wiley \& Sons, 2000.

GUMMESSON, E. Total relationship marketing. New York: Butterworth-Heineman, 2002.

HANSEN, U. Lost in relationship-marketing space: the limitations of relationship marketing from the perspective of the consumer. In: HENNIG-THURAU, T.; HANSEN, U. (Ed.). Relationship marketing: gaining competitive advantage through customer satisfaction and customer retention. Berlin: Springer-Verlag, 2000. p.415-35.

HENNIG-THURAU, T.; GWINNER, K.; GREMLER, D. Understanding relationship marketing outcomes: an integration or relational benefits and relational quality. Journal of Service Research, v.4, n.3, p. 230-247, 2002.

HOLBROOK, M. I Shop, therefore I am: compulsive buying and the search for self. Psychology \& Marketing, v. 4, n. 3, p. $189-212,2001$.

IACOBUCCI, D.; OSTROM, A. Commercial and interpersonal relationships: using the structure of interpersonal relationship to understand individual-to-individual, individual-to-firm, and firm-to-firm relationships in commerce. International Journal of Research in Marketing, v.13, n. 1, p.53-72, 1996.

KALE, S.; SHRIVASTAVA, S. Relationship marketing theory for consumer markets: suggestions for an alternative ontological and epistemological perspective, 2001. (Working paper).

KAPFERER, J. N. Strategic brand management: creating and sustaining brand equity long term. Kogan Page: London, 1997.

KARJALAINEN, TONI-MATI. Strategic brand identity and symbolic design cues. In. 6th ASIAN DESIGN CONFERENCE, 2003.

KELLER, K. L. Strategic brand management: building, measure, and managing band equity. 2.ed. Prentice-Hall: New Jersey, 2002.

McCRAKEN, G. The Long Interview. In: QUALITATIVE Research Methods. California: Sage Publications, 1988. v.13.

MELLO, S. C. B.; FONSÊCA, F. R. B. (Re)compreendendo o relacionamento marca-consumidor. Revista Faces, v. 6, n.1, 2007.

MILES, M. B.; HUBERMAN, A. M. Qualitative data analysis, Thousand Oaks: Sage Publications 1994.

PALMER, A. Integrating brand development and relationship marketing. Journal of Retailing and Consumer Service, v. 3, n. 4, p. 251257, 1996.

PATTERSON, M. Re-appraise the concept of brand image. Journal of Brand Management, v. 6, n. 6, p. 409-426, 1999.

; O'MALLEY, L. Brands, Consumers and Relationships: a Review. Irish Marketing Review, v. 18, n.1-2, p. 10-20, 2006.

RITZER, G. The McDonaldization: the reader. California: Pine Forge Press, 2002.

SCHÖN, Donald. The reflective practitioner. New York: Basic Books, 1983.

SEEBARANSINGH, N.; PATERSON, M.; O'MALLEY, I. Finding ourselves: women breast augmentation and identity. Gender, marketing and consumer behaviour, v. 6, p. 15-16, 2002.

SOLOMON, M. R. The role of products as social stimuli: a symbolic interactionism perspective. Journal of Consumer Research, v. 10, p. 319-329, 1983. 
SOUZA NETO, A. F.; MELLO, S. C. B.; CORDEIRO, A. T.; FONSÊCA, F. R. B. Voltando o carro para trás dos bois: busca da compreensão de nuances do "relacionamento" no contexto de consumo como forma de subsidiar a prática consciente do "marketing de relacionamento" por empresas de serviço. In: ENCONTRO DE MARKETING, 1, 2004, Porto Alegre, RS. Anais... Rio de Janeiro: Anpad, 2004.

SOUZA NETO, A. F.; MELLO, S. C. B. Olhando além do "primeiro estruturalismo": uma breve discussão sobre os conceitos fundamentais e princípios gerais nas análises estruturais, sua relevância e aplicabilidades potenciais na pesquisa em marketing. In: ENCONTRO DA ASSOCIAÇÃO DE PÓS-GRADUANDOS EM ADMINISTRAÇÃO, 31, 2007, Rio de Janeiro, RJ. Anais.... Rio de Janeiro: Anpad, 2007.

THOMPSON, C. J.; HIRSCHMAN, E. C. Understanding the socialized body: a poststructuralist analysis of consumers' self conceptions, body images and self care practices. Journal of Consumer Research, v. 22, n. 2, p. 139-153, 1995.

; LONCADER, W. B.; POLLIO, H. R. The lived meaning of free choice: an existential-phenomenological description of everyday consumer experiences of contemporary married women. Journal of Consumer Research, v. 17, n. 3, 346-361, 1990.

\footnotetext{
${ }^{1}$ A relação é parassocial quando há interação entre uma pessoa e um objeto inanimado. Nesse tipo de relação, diferentemente dos relacionamentos interpessoais, o consumidor não interage diretamente com a marca, mas sim com suas representações mediadas; isto é, os pontos de contato dela (e.g., funcionários, Ronald McDonald's, propagandas e produtos) (BENGTSSON, 2003; GUMMENSON, 2002).

${ }^{2} \mathrm{O}$ QSLV corresponde ao padrão de qualidade [socialização primária] da McDonalds.

${ }^{3}$ O NACC é uma instituição que oferece apoio às crianças carentes em tratamento na cidade e a seus familiares por meio de serviços de oncologia.
} 